\title{
Round the Clock Vehicle Emission Monitoring using IoT for Smart Cities
}

\author{
Jagadish Nayak \\ Electrical and Electronics Engineering Department \\ BITS Pilani, Dubai Campus \\ Dubai, United Arab Emirates
}

\begin{abstract}
Emissions from the vehicles contribute the major part of pollution in this world. Most of the countries have stringent rules to check the emission level through their transport authorities. So as to have zero emission, continuous monitoring of emission level is required. Smart cities need to maintain zero pollution throughout the year. In this paper, an IoT (Internet of Things) based system is proposed for continuous tracking and warning system. The prototype developed is connected to the exhaust of the vehicle and data is collected in the cloud, which can be further processed for a warning system. The device is tested with some vehicles and the results are comparable with the existing emission testing systems used in the market. This device can be used by all vehicle manufacturing companies by embedding it in their products.
\end{abstract} ity

Keywords-IoT; Emission; Sensor; Carbon; Tracking; Smartc-

\section{INTRODUCTION}

The proposed work in this paper will emphasize on vehicle emissions monitoring using Internet of Things (IoT). The motive behind the project, which led towards designing an emission level tracking system in motor vehicles, for mainly due to the upcoming Smart City initiative in most of the countries, and the increased concerns in carbon emissions all over the world. Aiming towards a city that provides mobility, health, safety and productivity is important, but alongside sustainability must be taken into consideration. The main objectives of proposed work is to understand Vehicle emissions and other growing concerns of smart city due to the Carbon Monoxide emission and to develop a round the clock Vehicle Emissions Sensing System (EMSENS), which will regularly track emissions throughout its operation. The concerned authority will warn the vehicle owner regarding $\mathrm{CO}$ emission of the vehicle.

As the years go by, people have begun to occupy every possible habitable space. This rise in population had led to a development of distinct types of cities. Every city or town now defined characteristics and are currently evolving socially and economically. Environment challenges and increased greenhouse-gas emissions which are forcing cities to develop sustainability strategies for energy generation and distribution, transportation, water management, urban planning, and ecofriendly (green) buildings. Figure 1 shows the components of a smart city. The smart cities must have least pollution. One of the sources of pollution is $\mathrm{CO}$ emissions from the vehicles, which need to be almost zero. But it is practically possible, when there is proper system to track the emission from vehicle all the time.

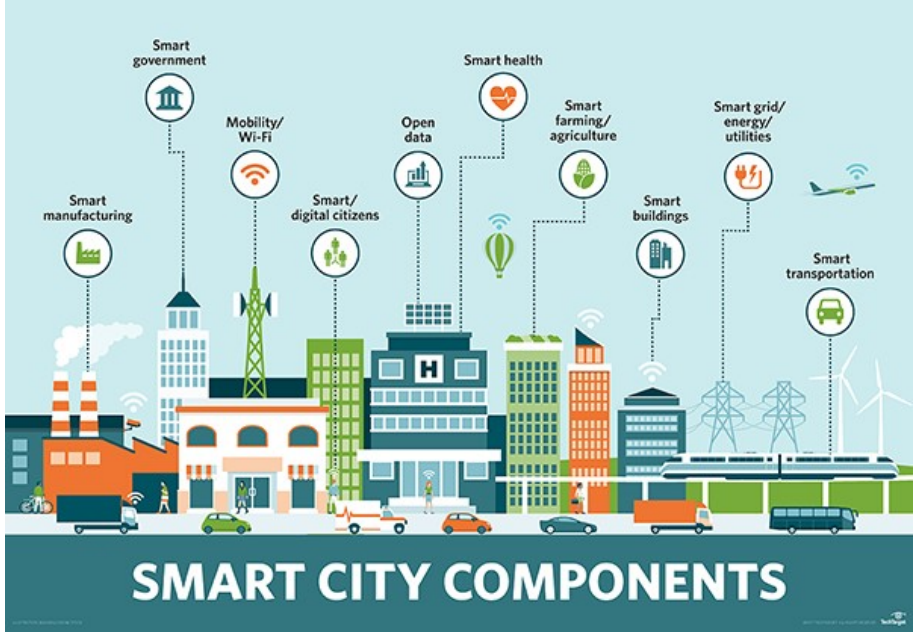

Fig. 1. Components of a Smart City (Source - Learn Internet Governance)

Environmental issues in the world have been on the rise over the years. With the development and bloom of the industry, the demands have also been increasing thus allowing them to be complying to the pressure and thereby giving rise to the already existing environmental conditions [1]. A few other factors which have contributed towards this are the constant depletion and exploitation of the natural resources which they are not really abundant of, coupled with increase in population. Global energy-related carbon dioxide (CO2) emissions are expected to increase by one-third between 2012 and 2040, which is shown in Figure 2, in EIA's International Energy Outlook 2016 (IEO2016) Reference case, largely driven by increased energy use in countries outside of the Organization for Economic Cooperation and Development (OECD). The $\mathrm{HC}-\mathrm{CO}$ (Hydro Carbon-Carbon Monoxide) tester is designed for checking exhaust emissions of automobiles in service. There is a probe which is placed in the exhaust pipe to determine the emissions. Obviously, the air/fuel mixture delivered to the engine gives the amount of carbon monoxide present. Whereas for HC, they depend on the fuel, and which is either not burned or just partly burned. An emission-controlled automobile running normally has $\mathrm{HC}$ emissions below $100 \mathrm{rpm}$ (parts per million) and $\mathrm{CO}$ emissions between 0.5 and $1.0 \%$. Non-emission-controlled engines have higher normal emission levels of about $400 \mathrm{ppm} \mathrm{HC}$ and $3.0 \% \mathrm{CO}$. Readings above the given values is an indication that the vehicle needs to be serviced. It would either be due to some fault in the engine or engine emissions. Tests for $\mathrm{HC}$ and $\mathrm{CO}$ are run at idle and 
higher speeds. At higher engine speeds, they must decrease. If the exhaust emissions are normal, no further checking of the emission controls is necessary.

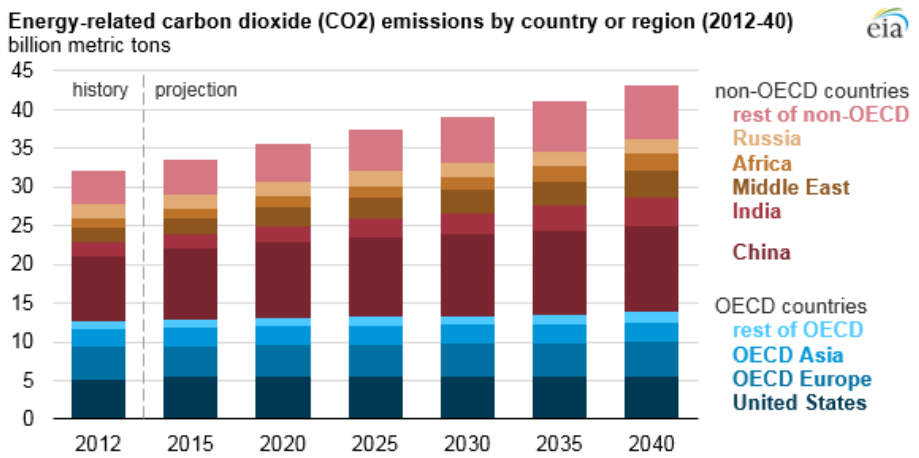

Fig. 2. Energy related Co2 emission by region (Source - U.S. Energy Information Administration, International Energy Outlook 2016)

\section{EMISSION TRACKING USING IOT}

The Internet of things (IoT) is the network of physical devices, vehicles, home appliances and other items embedded with electronics, software, sensors, actuators, and connectivity which enables these objects to connect and exchange data. The "things" in IoT can mean a lot, from a person with implants that automate his heart beat or animals with chips embedded in them which inform owners of their health, sensors in cars alerting drivers about obstacles or anything which can transfer data with minimizing or almost eliminating human to human or human to computer interaction[2]. Figure 3 shows an IoT platform. Some of the work mentioned in the literature[3],[4],[5],[6],[7] proposes methods based on the RFIDs and other methodologies. These systems do not provide any sort of continuous monitoring and warning systems, which is proposed in this paper.

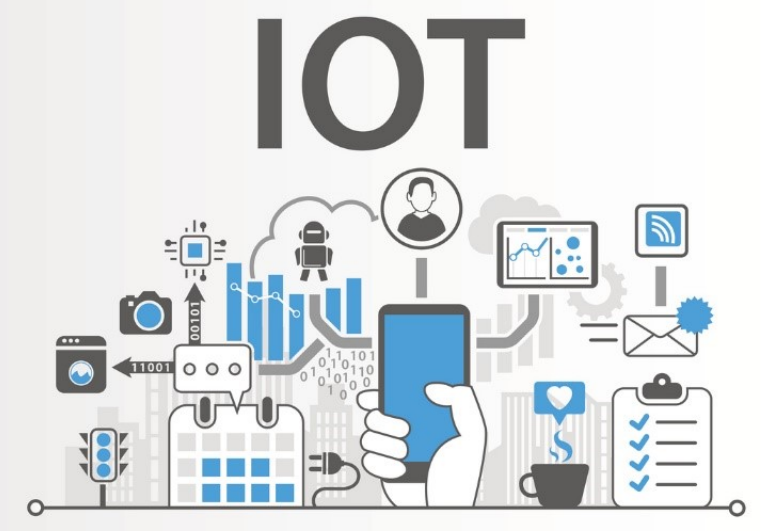

Fig. 3. Internet of Things

The traditional air quality checking framework is very costly and monotonous[8]. Measuring of these otherwise is very time consuming and takes up a lot of power. The prototype that has been discussed gives continuous observation of pollutants which are discharged from the vehicles. In this paper we proposed an IoT based system which will sense the $\mathrm{CO}$ emission of an vehicle continuously and updates the data base located in the Transport Authorities. The emission level can also be displayed on the display provided in the car. Warning message can also be sent to the owner of the vehicle regarding the emission level. Proposed system is shown in Figure 4.
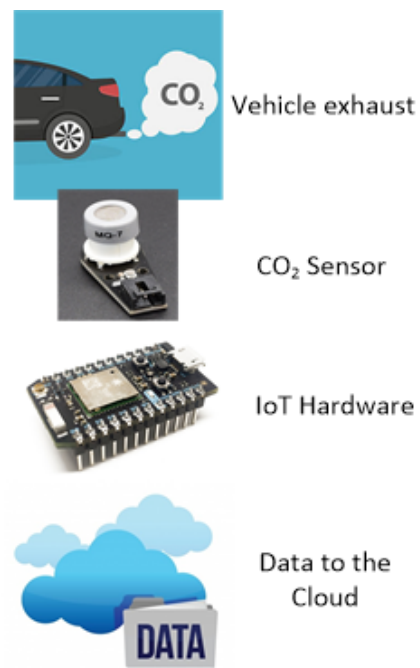

Fig. 4. Proposed prototype model - Design

\section{MATERIALS AND METHOD}

\section{A. Sensors}

The MQ series of Gas Sensors[9] used in this work are highly sensitive, simple and cost-effective sensors useful for sensing gases in the air. Figure 5 shows the typical MQ series of Gas Sensor. There is a wide range of sensors available each of which are made to detect a specific gas like Methane, NOx, SOx, LPG, CNG, Carbon Monoxide and Alcohol. This is a simple-to-use Carbon Monoxide (CO) sensor, suitable for sensing $\mathrm{CO}$ concentrations in the air. This sensor works in the temperature ranging from $-20^{\circ} \mathrm{C}$ to $50^{\circ} \mathrm{C}$

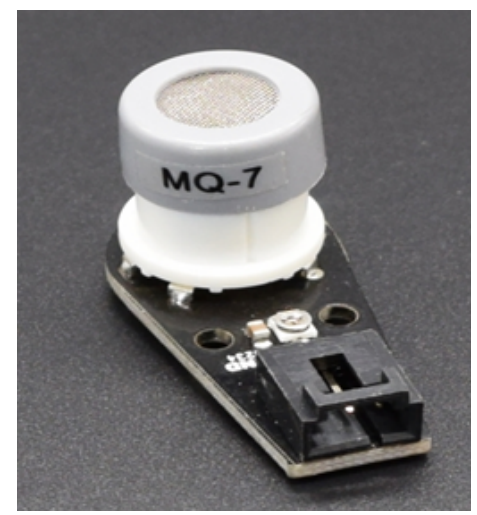

Fig. 5. Sensor

\section{B. Photon Particle Board}

Small and powerful Wi-Fi connected microcontroller Based on Cypress's WICED architecture, the Particle Photon Series 
combines a powerful STM32 ARM Cortex M3 microcontroller and a Cypress Wi-Fi chip[10]. This is tiny device with many functionalities. For the server, the particle photon is equipped with its own cloud. But there are external cloud services offered as well. We would be able to write the firmware on the web or local IDE, deploy it over the air, and build mobile apps. Figure 6 shows a Photon Particle Board.

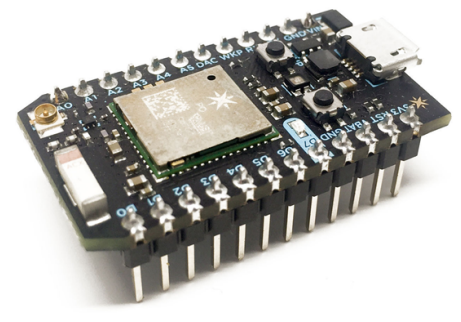

Fig. 6. Photon Particle Board

\section{IFTTT(If This Then That)}

This is a freeware[11] used to communicate various apps and devices. A trigger (like change of a value, or a new value under the given variable etc.) can be used to bring about the notification. Once the IFTTT detects the trigger, you can perform a variety of function with it. In this project, IFTTT has been incorporated to either send an email to the vehicle owner for high emissions rates or for storing the received values in the server (Google Sheet in this case).

\section{Implementation}

An enclosed structure consisting of the photon along with the required circuits and resistances (along with $3.3 \mathrm{~V}$ battery to power up the photon) A PVC pipe with smaller radius than that of the exhaust enclosed within it. Since the sensors have a limitation to temperature, these pipes could be used to reduce the temperature as they travel towards the sensor. Small slits can be made within the box to bring out the sensors which could be hung or placed in front of the exhaust. Another alternative to the PVC would be a water cooler system placed beneath the exhaust, which would help cool down the emissions from the exhaust, but that would be a tedious process considering this would be applicable to all vehicles on the road. Following are the implementation steps.

1) : Connection of sensors to the particle photon: The sensors would be integrated and connected to the IoT device.

2) : Create Particle App. The benefit provided by the photon is the cloud it is equipped with a cloud service. A code can be formulated from common sensors and publish a Particle event.

3) : IFTTT: The event will later act as an IFTTT trigger. Under this the conditions for the sensor emission values can be set. The above setup would be placed near the exhaust of the vehicle.

4) : The trigger in this case would be the notification. If the sensor values exceed the set standards, then an email would be sent to the respective ID (vehicle owner)

\section{Results AND Discussions}

On testing the system on the vehicle, results were obtained which would be discussed as follows. EMSENS is placed right in front of the vehicle exhaust as shown in Figure 7. The initial setup is done and once the sensors have pre heated the process begins. The particle IDE begins to update with new values of temperature and $\mathrm{CO}$ readings.

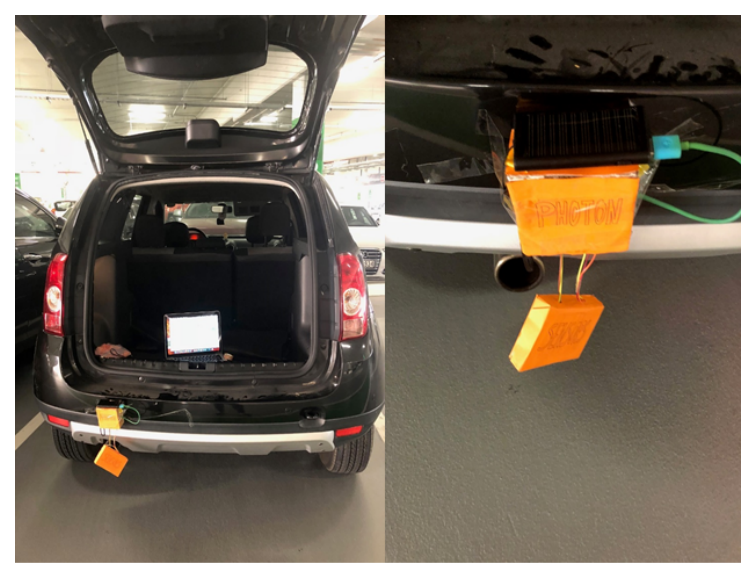

Fig. 7. EMSENS on the vehicle

The test was done when the car is in neutral phase. It is placed for a period of time for the values to be analyzed. The IFTTT trigger causes the new values to be recorded on new google sheets with respect to the type of reading, which is shown in Figure 8 and 9

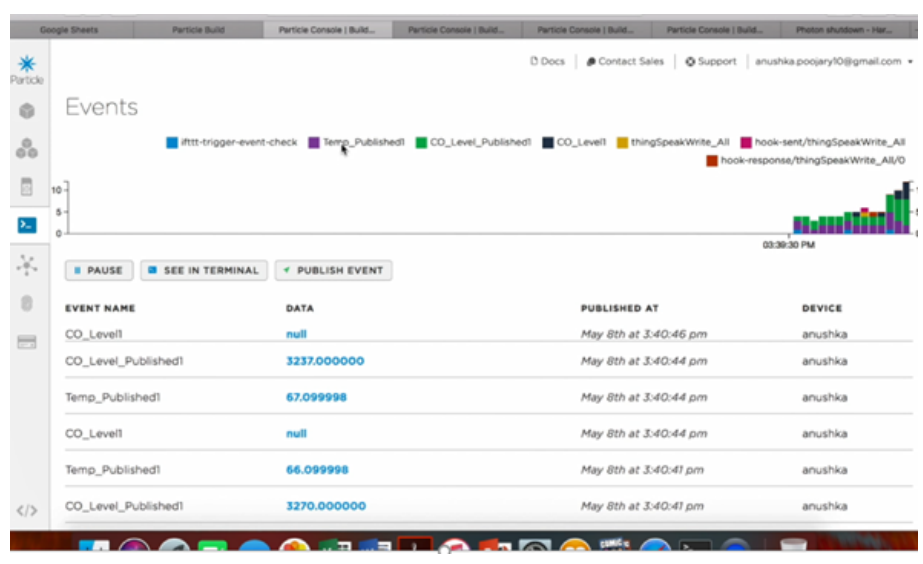

Fig. 8. Particle IDE display

On finding the rough ppm value with respect to the values we have obtained a ppm of $0.0083 \%$ was obtained. This when compared to a vehicle passing certificate, the $\mathrm{CO} \mathrm{ppm}$ percentage was $0.01 \%$. That is almost a $17 \%$ deviation from the original. The testing was done on three other vehicles as well giving ppm percentage.

- Mitsubishi Pajero: 0.053\%

- Toyota Rav4: 0.01\%

- Hyundai i10:0.086\%

Gas sensor technologies are still developing and have yet to reach their full potential in capabilities and usage. There are 


\begin{tabular}{|c|c|c|c|c|}
\hline & A & B & c & D \\
\hline 30 & Temp_Published & 84.5 & anushka & May 8,2018 at $03.42 \mathrm{PM}$ \\
\hline 31 & Temp_Published & 84.5 & anushka & May 8,2018 at $03.42 \mathrm{PM}$ \\
\hline 32 & Temp_Published & 84.800003 & anushka & May 8,2018 at $03.42 \mathrm{PM}$ \\
\hline 33 & Temp_Published & 85 & anushka & May 8,2018 at $03-42 \mathrm{PM}$ \\
\hline 34 & Temp_Published & 85 & anushka & May 8,2018 at $03: 42 \mathrm{PM}$ \\
\hline 35 & Temp_Published & 85 & anushka & May 8,2018 at $03.42 \mathrm{PM}$ \\
\hline 36 & Temp_Published & 85.5 & anushka & May 8,2018 at $03.42 \mathrm{PM}$ \\
\hline 37 & Temp_Published & 85.5 & anushka & May 8,2018 at $03: 43 \mathrm{PM}$ \\
\hline 38 & Temp_Published & 85.800003 & anushka & May 8,2018 at $03.43 \mathrm{PM}$ \\
\hline 39 & Temp_Published & 86.099998 & anushka & May 8,2018 at $03.43 \mathrm{PM}$ \\
\hline 40 & Temp_Published & 86.400002 & anushka & May 8,2018 at $03.43 \mathrm{PM}$ \\
\hline 41 & Temp_Published & 86.599998 & anushka & May 8,2018 at $03: 43 \mathrm{PM}$ \\
\hline 42 & Temp_Published & 86.599998 & anushka & May 8,2018 at $03: 43 \mathrm{PM}$ \\
\hline 43 & Temp_Published & 86.900002 & anushka & May 8,2018 at $03.43 \mathrm{PM}$ \\
\hline 44 & Temp_Published & 87.199997 & anushka & May 8,2018 at $03: 43 \mathrm{PM}$ \\
\hline 45 & Temp_Published & 86.5 & anushka & May 8,2018 at $03.43 \mathrm{PM}$ \\
\hline 46 & Temp_Published & 86.199997 & anushka & May 8,2018 at $03.43 \mathrm{PM}$ \\
\hline 47 & Temp_Published & 85.699997 & anushka & May 8,2018 at $03.43 \mathrm{PM}$ \\
\hline 48 & Temp_Published & 85.400002 & anushka & May 8,2018 at $03.43 \mathrm{PM}$ \\
\hline 49 & Temp_Published & 84.900002 & anushka & May 8,2018 at $03.43 \mathrm{PM}$ \\
\hline 50 & Temp_Published & 84.300003 & anushka & May 8,2018 at $03.43 \mathrm{PM}$ \\
\hline 51 & Temp_Published & 83.800003 & anushka & May 8,2018 at $03.43 \mathrm{PM}$ \\
\hline 52 & Temp_Published & 83.300003 & anushka & May 8,2018 at $03.43 \mathrm{PM}$ \\
\hline 53 & Temp_Published & 82.900002 & anushka & May 8,2018 at $03: 43 \mathrm{PM}$ \\
\hline
\end{tabular}

Fig. 9. Google sheet records via IFTTT

technologies which give accurate readings without the hassle, but they are quite expensive. For the low-cost method to be effective, various readings will have to be taken and compared against a known value. This way the erroneous readings that could hinder the process can be significantly reduced.

The particle photon is available for 25US\$, while the lowcost sensors cost from 10-20US\$. The entire system is setup for less than 78US\$. Also, by using vehicles more efficiently one can save money. This would either be in terms of fuel expenditure or preventing the wear and tear. Due to the nature of the prototype, the process is automatic with almost no inspection required except for the one present at the servers to observe the values. The main aim of this project is to constantly monitor carbon emissions in the vehicle and notify the user about the levels to notify them when their vehicle is due for service. Since they would be more aware of the emission level of their vehicle, not only are they more aware but also conscious towards the environment. There are concerns with the quality of the data that such sensors can produce. Studies say that when cost is compromised, so is the quality. Thus, important factors like the accuracy and sensitivity are both affected.
Costly sensors usually go through quite a lot of review and evaluation thus making it reliable While the same does not apply for the latter. Another alternative could be to incorporate the sensors within the simple system so give accurate readings while taking in IoT into consideration as well. While we are diverging into an environmentally friendly, some academics are also concerned about the e-waster that is produced post life of these sensors. Another concern to be noted is of IFTTT, is that there tend to bug within the set hence not allowing the applets to run. For Google Sheets it has a limit of only 100 posts a day.

\section{CONClusion}

The environmental pollution due to the emissions from the vehicles need to be tracked continuously to control the carbon foot print on this earth. Especially in smart cities continuous monitoring is a challenging task. The proposed prototype can track the emission from vehicle and warns the vehicle user to make proper regular maintenance of the vehicle. Transport authority can also take benefit of this device to keep track of vehicle emissions in respective cities.

\section{REFERENCES}

[1] FastFacts U.S. Transportation Sector Greenhouse Gas Emissions 1990 2016 Offce of Transportation and Air Quality EPA-420-F-18-013 July 2018

[2] Peter Waher Learning Internet of Things, Packt Publishing, January 2015

[3] S.P. Bangal, Gite Pravin E, Ambhure Shankar G, Gaikwad Vaibhav M, IoT Based Vehicle Emissions Monitoring and Inspection System, International Journal of Innovative Research in Electrical, Electronics, Instrumentation and Control Engineering, Vol. 5, Issue 4, April 2017.

[4] Souvik Manna, Suman Sankar Bhunia, Nandini Mukherjee, Vehicular pollution monitoring using IoT, International Conference on Recent Advances and Innovations in Engineering (ICRAIE-2014) 9-11 May 2014.

[5] Rose Sweetlin .T, Priyadharshini .D ,Preethi .S, Sikkandar Sulaiman .A , Control of vehicle pollution through Internet of things (IOT), International Journal Of Advance Research, Ideas And Innovations In Technology, Volume-3, Issue-2, 2017.

[6] R.Priyanka, S.K. Thai Bhuvana, Archanaa Raveendran, Dr. R. Kavitha , Vehicle Pollutants Control Using Sensors And Arduino, Third International Conference on Sensing, Signal Processing and Security (ICSSS) 4-5 May 2017

[7] Sneha S. Kamalakar and M. S. Vanjale, Inspection and Notification of Vehicle Emissionin Smart Cities, Indian Journal of Science and Technology, Vol 9(S1) December 2016

[8] ELAWEJ, Khalifa A. K. , A framework for the evaluation of air pollution caused by motor vehicles., Doctoral, Sheffield Hallam University (United Kingdom), 2014

[9] Technical data manual MQ-7 Gas Sensor, HANWEI Electronics Co. Ltd http://www.hwsensor.com

[10] Technical data Sheet Particle Photon Board :https://docs.particle.io/datasheets/

[11] A world that works for you , IFTTT website https://ifttt.com/ 